\title{
Exponential dependence of the interlayer exchange coupling on the spacer thickness in MBE-grown Fe/SiFe/Fe sandwiches
}

\author{
Citation for published version (APA): \\ de Vries, J. J., Kohlhepp, J. T., Broeder, den, F. J. A., Coehoorn, R., Jungblut, R., Reinders, A., \& Jonge, de, W. \\ J. M. (1997). Exponential dependence of the interlayer exchange coupling on the spacer thickness in MBE- \\ grown Fe/SiFe/Fe sandwiches. Physical Review Letters, 78(15), 3023-3026. \\ https://doi.org/10.1103/PhysRevLett.78.3023
}

DOI:

10.1103/PhysRevLett.78.3023

Document status and date:

Published: 01/01/1997

\section{Document Version:}

Publisher's PDF, also known as Version of Record (includes final page, issue and volume numbers)

\section{Please check the document version of this publication:}

- A submitted manuscript is the version of the article upon submission and before peer-review. There can be important differences between the submitted version and the official published version of record. People interested in the research are advised to contact the author for the final version of the publication, or visit the DOI to the publisher's website.

- The final author version and the galley proof are versions of the publication after peer review.

- The final published version features the final layout of the paper including the volume, issue and page numbers.

Link to publication

\footnotetext{
General rights

- You may freely distribute the URL identifying the publication in the public portal. follow below link for the End User Agreement:

www.tue.nl/taverne

\section{Take down policy}

If you believe that this document breaches copyright please contact us at:

openaccess@tue.nl

providing details and we will investigate your claim.
}

Copyright and moral rights for the publications made accessible in the public portal are retained by the authors and/or other copyright owners and it is a condition of accessing publications that users recognise and abide by the legal requirements associated with these rights.

- Users may download and print one copy of any publication from the public portal for the purpose of private study or research.

- You may not further distribute the material or use it for any profit-making activity or commercial gain

If the publication is distributed under the terms of Article $25 \mathrm{fa}$ of the Dutch Copyright Act, indicated by the "Taverne" license above, please 


\title{
Exponential Dependence of the Interlayer Exchange Coupling on the Spacer Thickness in MBE-grown Fe/SiFe/Fe Sandwiches
}

\author{
J. J. de Vries, ${ }^{1}$ J. Kohlhepp, ${ }^{1}$ F. J. A. den Broeder, ${ }^{2}$ R. Coehoorn, ${ }^{2}$ R. Jungblut,${ }^{2}$ A. Reinders,${ }^{2}$ and W. J. M. de Jonge ${ }^{1}$ \\ ${ }^{1}$ Eindhoven University of Technology, P.O. Box 513, 5600 MB Eindhoven, The Netherlands \\ ${ }^{2}$ Philips Research Laboratories Eindhoven, Prof. Holstlaan 4, 5656 AA Eindhoven, The Netherlands
}

(Received 23 December 1996)

\begin{abstract}
The structure and interlayer exchange coupling in MBE-grown $\mathrm{Fe} / \mathrm{SiFe} / \mathrm{Fe}$ has been investigated. From structural analysis with LEED and from magnetic analysis with the magneto-optical Kerr effect, it is concluded that the $\mathrm{Si}$ spacer transforms into an ordered $\mathrm{Si}_{0.5} \mathrm{Fe}_{0.5}$ alloy. A strong antiferromagnetic coupling is found (maximum $-2.0 \mathrm{~mJ} / \mathrm{m}^{2}$ ), the strength of which varies exponentially as a function of the spacer thickness. This behavior can be explained within the framework of recent coupling theories. [S0031-9007(97)02971-2]
\end{abstract}

PACS numbers: 75.70.-i, 75.30.Et

Oscillatory interlayer exchange coupling in metallic magnetic multilayers as a function of the spacer thickness has been observed for a whole range of materials [1]. The origin of the oscillation is intimately related to the wave nature of spin-polarized conduction electrons in the spacer and the oscillation period is determined by extremal spanning vectors, critical vectors, of the spacer Fermi surface (FS) [2], and references therein.

However, the thickness dependence of the coupling strength is theoretically not necessarily oscillatory. Exponents have also been predicted, even for metals [2-4]. Bruno and Slonczewski predict exponential behavior on the basis of tunneling electron waves [2,3]. Shi et al. showed that a peak in the density of states (DOS) close to the Fermi energy can also give rise to exponential behavior via a superexchange mechanism [4].

So far, observations of exponentially decaying, nonoscillatory, ferromagnetic (F), or antiferromagnetic (AF) interlayer coupling are rare. Although monotonically decreasing F coupling across Pt and Pd spacers has been found [5,6], one has to note that $\mathrm{Pt}$ and $\mathrm{Pd}$ are strongly polarizable and, in the case of $\mathrm{F}$ coupling, direct coupling through ferromagnetic bridges, pinholes, can be responsible. Another possible example is $\mathrm{Fe} / \mathrm{Cr}$, which sometimes displays a short period oscillation with a small AF bias $[7,8]$. However, the AF bias has also been ascribed to a long period oscillation or to interface roughness $[7,8]$.

In this Letter, we show that the interlayer coupling in $\mathrm{Fe} / \mathrm{SiFe} / \mathrm{Fe}$ is strongly $\mathrm{AF}$ and decreases exponentially with increasing spacer thickness. This supports recent predictions by Shi et al. [9] and can also be interpreted in terms of the Bruno electron-optics model [2].

The interlayer exchange coupling in $\mathrm{Fe} / \mathrm{Si}$ multilayers and sandwiches has been studied extensively [10-17]. In general, for small nominal $\mathrm{Si}$ layer thicknesses iron silicide $(\mathrm{SiFe})$ is formed, whereas for larger thicknesses amorphous $\mathrm{Si}(a-\mathrm{Si})$ is deposited. Across $\mathrm{SiFe}$ spacers a single strong AF coupling peak $\left(-0.5 \mathrm{~mJ} / \mathrm{m}^{2}\right)$ has been observed [12-17], and for $a$-Si spacers a weak oscillatory coupling (maximum $-5 \mu \mathrm{J} / \mathrm{m}^{2}$ ) is found [10,11]. The interpretation of the coupling behavior is still a matter of debate. For $\mathrm{SiFe}$, in particular, the thickness dependence (oscillatory or not) is not yet clear.

For our experiments a MBE-grown sample was composed as follows: $\mathrm{Ge}(100) / 80 \AA \mathrm{Fe} / 0-40 \AA \mathrm{Si}$ wedge/ 0-80 $\AA \mathrm{Fe}$ wedge $/ 20 \AA \mathrm{Au}$. The wedges were aligned perpendicularly and allow independent, accurate variation of the thicknesses to study the coupling behavior ( $\mathrm{Si}$ wedge) or the $\mathrm{SiFe}$ formation (Fe wedge). The substrate was held at room temperature except during the deposition of the bottom Fe layer and the Si wedge when it was held at $200{ }^{\circ} \mathrm{C}$. Use was made of a sulfur surfactant [18]. During growth the sample was studied with LEED and, after completion, with the longitudinal magneto-optical Kerr effect at room temperature.

Analysis with LEED resulted in sharp (100) patterns of the Ge substrate and bottom Fe layer. No clear LEED pattern of the Si wedge was found. After deposition of the top Fe layer, however, the same Fe LEED pattern surprisingly reappeared. This suggests that the nominal $\mathrm{Si}$ spacer with an ill-defined structure transforms into a crystalline, epitaxial $\mathrm{SiFe}$ structure when depositing Fe. Further growth of Fe proceeds epitaxially. Such a crystallization is in agreement with earlier observations $[12,17]$. The pattern of the top Fe layer was observed up to $30 \AA$ nominal Si thickness $-20 \AA$ for sputtered samples $[13,17]$ - but disappeared for larger thicknesses. Presumably, at this thickness the spacer also contains $a$-Si. Therefore, our coupling results are limited to $<30 \AA$ nominal Si.

In Fig. 1 a magneto-optical Kerr hysteresis loop evidencing AF coupling is shown. For positive fields the loop displays two well-defined states, the antiparallel (AP) and parallel (P) alignment state of the magnetic moments of the two Fe layers, which are connected through a linear transition. While the thicker $80 \AA$ bottom Fe layer is effectively pinned by the field, the thinner $25 \AA$ top Fe layer reverses its moment. The shift of the linear transition from zero 


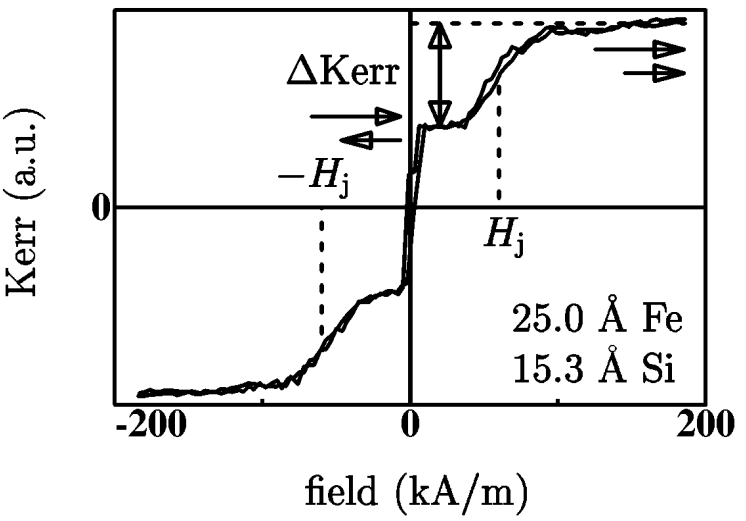

FIG. 1. A Kerr hysteresis loop displaying AF coupling measured at the indicated nominal $\mathrm{Si}$ and $\mathrm{Fe}$ wedge thicknesses. Arrows indicate the alignment of the magnetic moments.

by $H_{\mathrm{j}}$ is related to the bilinear (AF) coupling strength $J$. Defining the coupling field $H_{\mathrm{j}}$ as halfway through the linear transition one has $J=-t_{\mathrm{Fe}} \mu_{0} M_{\mathrm{s}} H_{\mathrm{j}}$, where $t_{\mathrm{Fe}}$ is the top Fe layer thickness and $\mu_{0} M_{\mathrm{s}}$ the saturation magnetization of Fe. For stronger coupling at smaller spacer thickness, the linear transition becomes more rounded. While the origin of this is not clear, from such loops the coupling strength cannot be determined. Hence, coupling data are only given above a certain thickness $(>10 \AA)$.

The transition from the AP to the P state and therefore the difference of the Kerr signals in both states, $\Delta$ Kerr, is due to the top Fe layer. In Fig. $2 \Delta$ Kerr is plotted against the nominal $\mathrm{Fe}$ thickness of the top layer for two nominal $\mathrm{Si}$ thicknesses. A linear relation-for small $\mathrm{Fe}$ thicknessthrough the origin is expected; however, a linear relation with an offset of the Fe thickness is found. This offset is seen to increase with increasing Si thickness. Linear regression fits yield offsets of $8.7 \pm 1.1 \AA \mathrm{Fe}$ at $15.3 \AA$ nominal $\mathrm{Si}$ and $14.1 \pm 0.4 \AA \mathrm{Fe}$ at $22.1 \AA$ nominal Si. It appears that some $\mathrm{Fe}$ is missing and that the missing amount increases with Si thickness.

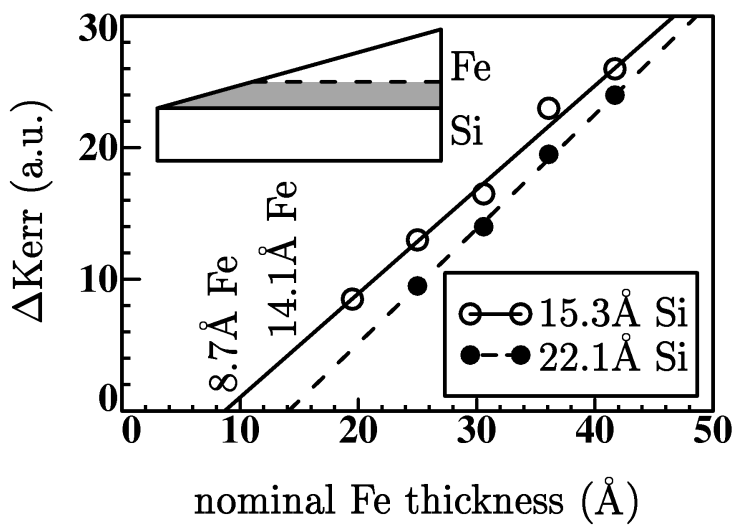

FIG. 2. Plot of $\Delta$ Kerr (see Fig. 1) as a function of the nominal $\mathrm{Fe}$ wedge thickness for two nominal $\mathrm{Si}$ thicknesses. The lines are linear regression fits. Values for the fitted offsets are given and correspond to the missing Fe thickness (shaded area in the inset).
This observation can be understood if a nonmagnetic $\mathrm{SiFe}$ is formed. Using the molar volumes of bcc Fe $V_{\mathrm{Fe}}=$ $7.1 \mathrm{~cm}^{3} /$ mole and $a-\mathrm{Si} V_{\mathrm{Si}}=12.1 \mathrm{~cm}^{3} /$ mole and the ratio of missing $\mathrm{Fe}$ thickness and corresponding Si thickness above ( 0.57 or 0.64$)$, one arrives at a stoichiometry of $\mathrm{Si}: \mathrm{Fe}=1: 1$ [see Eq. (1), ratio 0.59]. The observed epitaxy indicates an ordered phase. On the basis of our x-ray diffraction measurements on sputtered multilayers we expect a bcc SiFe structure. These findings are consistent with a $\mathrm{CsCl}$ structure (B2) for the SiFe. However, detailed growth studies on sputtered and evaporated $\mathrm{Fe} / \mathrm{Si}$ multilayers have demonstrated convincingly that $\mathrm{SiFe}$ with a $\mathrm{CsCl}$ structure is formed; see, e.g., Chaiken et al. [17]. This phase of $\mathrm{SiFe}$ is metallic and its lattice mismatch of only $5.3 \%$ with Fe indeed allows epitaxial growth. Thus, the reaction becomes 1 mole $\mathrm{Si}+1$ mole $\mathrm{Fe} \rightarrow 2$ mole CsCl-type $\mathrm{Si}_{0.5} \mathrm{Fe}_{0.5}$, with $V_{\mathrm{SiFe}}=6.4 \mathrm{~cm}^{3} /$ mole, which reads in layer thicknesses

$$
\begin{aligned}
& t_{\mathrm{Si}} \mathrm{Si}+\frac{V_{\mathrm{Fe}}}{V_{\mathrm{Si}}} \times t_{\mathrm{Si}} \mathrm{Fe} \rightarrow 2 \frac{V_{\mathrm{SiFe}}}{V_{\mathrm{Si}}} \times t_{\mathrm{Si}} \mathrm{Si}_{0.5} \mathrm{Fe}_{0.5}, \\
& t_{\mathrm{Si}} \mathrm{Si}+0.59 \times t_{\mathrm{Si}} \mathrm{Fe} \rightarrow 1.06 \times t_{\mathrm{Si}_{1}} \mathrm{Si}_{0.5} \mathrm{Fe}_{0.5},
\end{aligned}
$$

where $t_{\mathrm{Si}}$ is the nominal thickness of the initial Si layer. The reaction asymmetry (Fe on $\mathrm{Si}$ reacts, $\mathrm{Si}$ on Fe does not) can be understood from the wetting behavior [19].

The assumption that $\mathrm{Si}_{0.5} \mathrm{Fe}_{0.5}$ is formed can also be applied to other work such as that of den Broeder and Kohlhepp $[15,16]$. They studied basically Fe/Si multilayers with variations of FeSi alloy magnetic and spacer layers. Figure 3(a) displays the saturation fields $H_{\mathrm{s}}$ against the nominal spacer thickness. One may calculate the resulting thickness of the magnetic and spacer layers if precisely a $\mathrm{Si}_{0.5} \mathrm{Fe}_{0.5}$ spacer is formed by absorbing $\mathrm{Fe}$ from the magnetic layers. Apart from changing the thickness of the spacer, this will also change the magnetic layer thickness resulting in different saturation fields. For comparison the transformed saturation fields $H_{\mathrm{s} \text {,trans }}$ are also normalized to magnetic layers of $30 \AA \mathrm{Fe}, \mathrm{Fig}$. 3(b). One of the interesting observations is that the descending data beyond the AF maximum coincide on a unified curve. This suggests that the same coupling across $\mathrm{Si}_{0.5} \mathrm{Fe}_{0.5}$ may be responsible for the observed dependence in $\mathrm{Fe} / \mathrm{Si}$ based multilayers reported so far. For smaller spacer thickness the data deviate from this unified curve, as explained below.

For the present sample we find a similar behavior of the saturation field $H_{\mathrm{s}}$; see Fig. 4. The asymmetric peak with a long tail on the right clearly rules out oscillatory behavior but indicates a monotonic decay instead. At the maximum the coupling strength is approximately $J \simeq-\frac{1}{2} t_{\mathrm{Fe}} \mu_{0} M_{\mathrm{s}} H_{\mathrm{s}}=-2.0 \mathrm{~mJ} / \mathrm{m}^{2}$. Below we will substantiate our claim that the reduced AF coupling strength at smaller thicknesses, yielding the misleading peaklike appearance, is caused by $\mathrm{F}$ coupling, probably through pinholes. To this purpose we also plot the normalized remanent Kerr signal in Fig. 4. If the Kerr remanence 

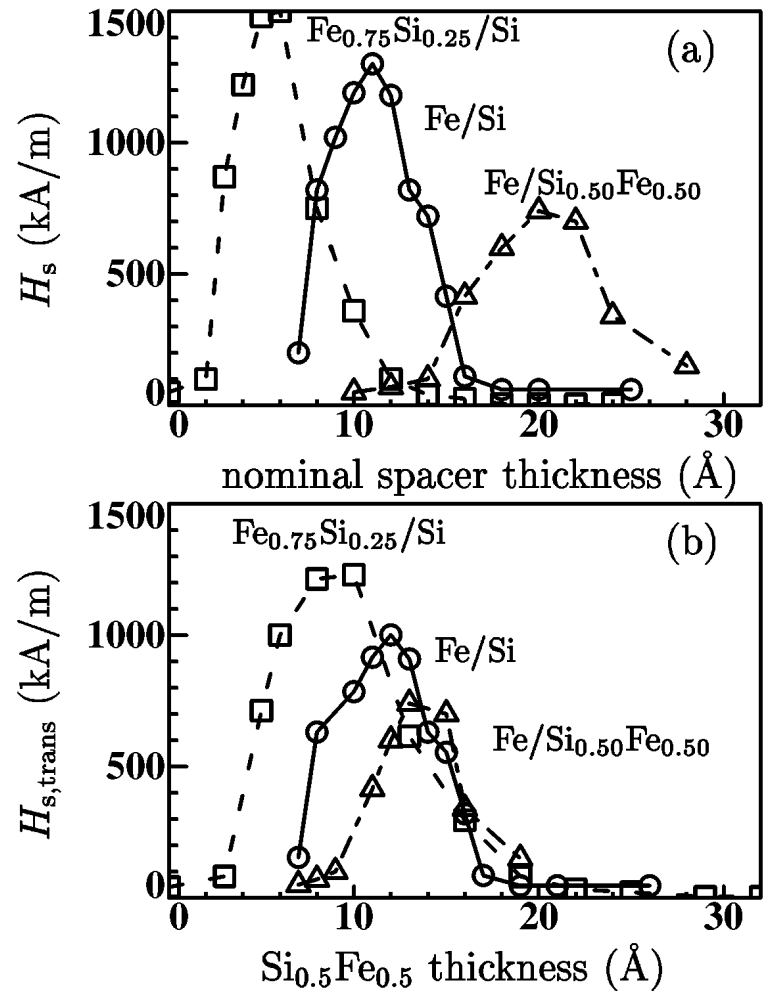

FIG. 3. (a) Saturation field against nominal spacer thickness for various $\mathrm{Fe} / \mathrm{Si}$ based multilayers; original data of $[15,16]$. Labels refer to the nominal composition of the magnetic/spacer layers. (b) Transformed data assuming that a $\mathrm{Si}_{0.5} \mathrm{Fe}_{0.5}$ spacer is formed and normalized to magnetic layers of $30 \AA \mathrm{Ae}$. For example, the spacer thickness of the Fe/Si (middle) curve is transformed using Eq. (1). Note the unified behavior on the right.

were a measure of the AF coupling strength, it should correlate with $H_{\mathrm{s}}$, i.e., an increasing remanence with decreasing $H_{\mathrm{s}}$ and vice versa. In particular, an increase would be expected from $7 \AA \mathrm{Si}_{0.5} \mathrm{Fe}_{0.5}$ upwards, but this is not observed. It is more likely that the Kerr remanence is

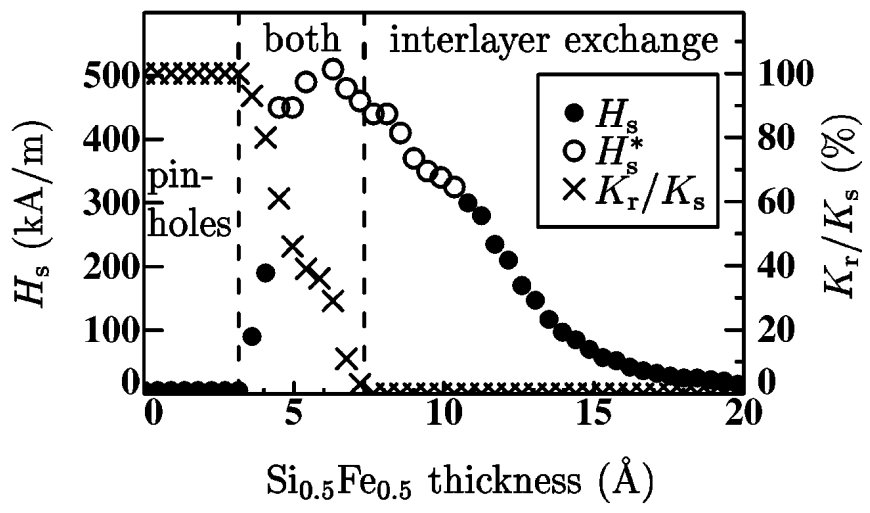

FIG. 4. Direct and extrapolated saturation fields $\left(H_{\mathrm{s}}\right.$ and $\left.H_{\mathrm{s}}^{*}\right)$ and the normalized remanent Kerr signal $\left(K_{\mathrm{r}} / K_{\mathrm{s}}\right)$, which are measures of the AF coupling strength and fractional F coupling (probably pinhole formation), respectively, against calculated $\mathrm{Si}_{0.5} \mathrm{Fe}_{0.5}$ thickness at $40 \AA$ nominal Fe. Three coupling-type regions are discerned. caused by a F coupled fraction in AF coupled regions of the sample and therefore a F-type loop contribution to an AFtype loop [15]. Indeed the disappearance of the Kerr remanence, less $\mathrm{F}$ coupling, coincides with the increase of $H_{\mathrm{s}}$ at 6-7 $\AA$ where the interlayer AF coupling is restored. The increasingly dominant $\mathrm{F}$ coupling at thinner spacers correlates with the increasingly likely pinhole formation and is therefore probably of pinhole origin. In line with this, we remark that the more $\mathrm{Fe}$ is present in or near the initial spacer, the more likely it is that pinholes are formed. In other words, the cutoff thickness where pinholes start to reduce the AF coupling should increase in the order $\mathrm{Fe}_{0.75} \mathrm{Si}_{0.25} / \mathrm{Si}, \mathrm{Fe} / \mathrm{Si}, \mathrm{Fe} / \mathrm{Si}_{0.5} \mathrm{Fe}_{0.5}$, as observed in Fig. 3 . Because of $\mathrm{F}$ coupling (probably pinholes) at small spacer thicknesses and weak or no coupling $(a-\mathrm{Si})$ at somewhat larger spacer thicknesses, the thickness dependence of the AF coupling strength across $\mathrm{SiFe}$ can be easily misinterpreted as a first single peak of an oscillation [12].

For the present double wedge $\mathrm{Fe} / \mathrm{SiFe} / \mathrm{Fe}$ sample the thickness dependence of the coupling strength has been calculated from $H_{\mathrm{j}}$ at various $\mathrm{Fe}$ wedge thicknesses. The result for $30.6 \AA$ nominal Fe is shown in Fig. 5.

Recently, Shi et al. have calculated that $\mathrm{Si}_{0.5} \mathrm{Fe}_{0.5}$ in the $\mathrm{CsCl}$ structure with an Fe lattice constant, displays a peak in the DOS [9]. Consequently, an exponential thickness dependence of the coupling is expected $[4,20]$ :

$$
J \sim \exp \left(-t_{\mathrm{SiFe}} / \lambda_{\mathrm{S}}\right) .
$$

A fit (solid line in Fig. 5) of the data resulted in $\lambda_{\mathrm{S}}=$ $3.6 \pm 0.2 \AA$. Unfortunately, Shi et al. do not give a value for comparison. The Bruno model predicts [2]

$$
J \sim t_{\mathrm{SiFe}}^{-2} \exp \left(-t_{\mathrm{SiFe}} / \lambda_{\mathrm{B}}\right),
$$

yielding $\lambda_{\mathrm{B}}=6.9 \pm 0.6 \AA$ (dashed line in Fig. 5). Bruno showed that both traveling and tunneling electron waves can be treated within the concept of complex FSs [2].

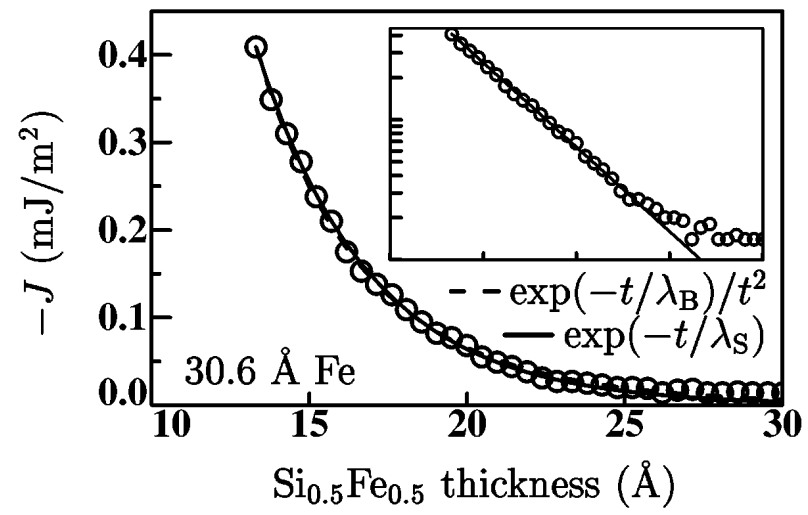

FIG. 5. AF coupling strength, corrected for missing $\mathrm{Fe}$, against calculated $\mathrm{Si}_{0.5} \mathrm{Fe}_{0.5}$ spacer thickness for $30.6 \AA$ nominal Fe. The solid line is an exponential fit with Eq. (2), plotted on a log scale in the inset (same ranges and units), and the dashed line (nearly coinciding with the solid line) is a fit with Eq. (3). 


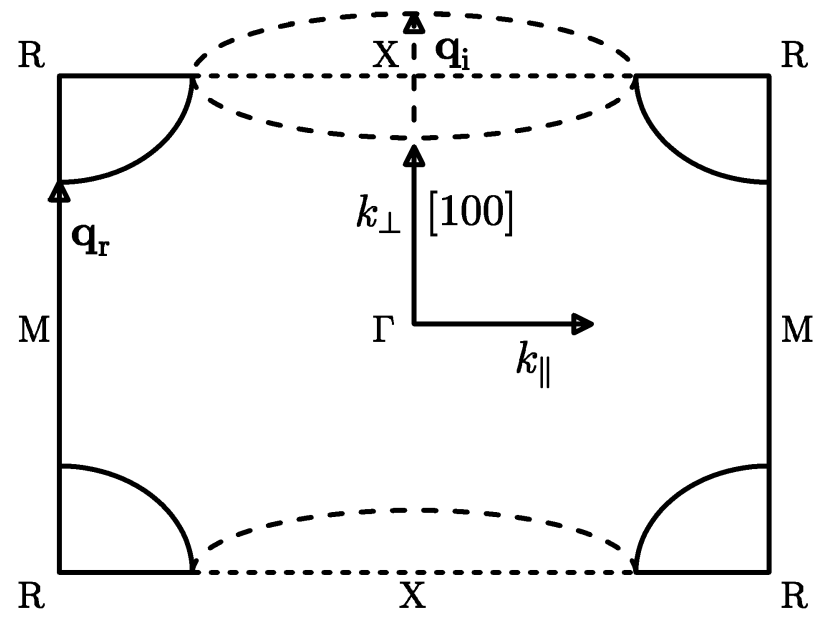

FIG. 6. Complex Fermi surface of $\mathrm{Si}_{0.5} \mathrm{Fe}_{0.5}$ in the $\mathrm{CsCl}$ structure with a Fe lattice constant, pertaining to the (100) orientation, schematically. Conventions as in [2]. Real parts are given by solid lines, taken from [9], and complex parts by dashed lines. The dashed (solid) arrow indicates the imaginary (real) critical vector.

Critical vectors of the real part of the complex FS yield oscillations and determine the period, whereas critical vectors of the imaginary part give rise to exponents and determine the typical length of the exponential decay $\lambda_{\mathrm{B}}$.

The complex FS of $\mathrm{Si}_{0.5} \mathrm{Fe}_{0.5}$ in the $\mathrm{CsCl}$ structure is given in Fig. 6 (conventions as in [2]). Solid lines represent the real part which is taken from Shi et al. [9]. We have qualitatively added the imaginary part (dashed lines). The coupling behavior is governed by critical vectors parallel to the [100] direction $(\Gamma X)$ for the present (100) oriented samples [21]. From the imaginary critical vector in Fig. 6 an exponential contribution is expected. A crude estimation of the imaginary critical vector can be obtained from the position of the peak in the DOS calculated by Shi et al. [9]: $E_{\mathrm{F}}-E_{\text {peak }}=-0.22 \mathrm{eV}$. The imaginary critical vector can be calculated using

$$
k_{\mathrm{i}}=\frac{1}{\hbar} \sqrt{2 m\left(E_{\text {peak }}-E_{\mathrm{F}}\right)}
$$

and $q_{\mathrm{i}}=2 k_{\mathrm{i}}$, which gives rise to a typical length for the exponential decay of $q_{\mathrm{i}}^{-1}=\left(0.48 \AA^{-1}\right)^{-1}=2.1 \AA$ [21]. Although there may not be a quantitative agreement for $\lambda_{\mathrm{B}}$, the exponential behavior is qualitatively clear. Note that also a real critical vector exists; see Fig. 6. A strong oscillatory coupling, however, is not expected because of the low DOS at the Fermi level [4,9].

According to the Bruno theory imaginary critical vectors give rise to stronger coupling for higher temperatures. Initially, such behavior was derived incorrectly from the remanence for $\mathrm{Fe} / \mathrm{SiFe}$ multilayers [14]. Other temperature studies yield the opposite: by focusing on the saturation field, which is more directly related to the $\mathrm{AF}$ coupling strength, a weaker coupling for higher temperatures has been established $[15,16]$, in agreement with the model of Shi et al. [4].

In conclusion, for nominal $\mathrm{Fe} / \mathrm{SiFe} / \mathrm{Fe}$ sandwiches alloying of $\mathrm{Si}$ and $\mathrm{Fe}$ has been deduced. There are strong indications that (metallic) $\mathrm{Si}_{0.5} \mathrm{Fe}_{0.5}$ in the $\mathrm{CsCl}$ structure is formed. A new type of interlayer coupling, strongly $\mathrm{AF}$ and exponentially decreasing with increasing spacer thickness, has been observed and can be understood qualitatively both within the superexchange model of Shi et al. and the tunneling electron model of Bruno.

[1] S. S. P. Parkin, Phys. Rev. Lett. 67, 3598 (1991).

[2] P. Bruno, Phys. Rev. B 52, 411 (1995).

[3] J. C. Slonczewski, Phys. Rev. B 39, 6995 (1989).

[4] Z.P. Shi, P. M. Levy, and J. L. Fry, Europhys. Lett. 26, 473 (1994).

[5] P. J.H. Bloemen, E. A. M. van Alphen, and W. J. M. de Jonge, J. Magn. Magn. Mater. 104-107, 1775 (1992).

[6] Z. Celinski, B. Heinrich, and J. F. Cochran, J. Appl. Phys. 70, 5870 (1991).

[7] J. A. Wolf et al., J. Magn. Magn. Mater. 121, 253 (1993).

[8] B. Heinrich et al., Mater. Res. Soc. Symp. Proc. 313, 119 (1993).

[9] Z. P. Shi, B. M. Klein, and Z. W. Lu (to be published).

[10] S. Toscano et al., J. Magn. Magn. Mater. 114, L6 (1992).

[11] B. Briner and M. Landolt, Phys. Rev. Lett. 73, 340 (1994).

[12] E. E. Fullerton et al., J. Magn. Magn. Mater. 117, L301 (1992).

[13] J. E. Mattson et al., Phys. Rev. Lett. 71, 185 (1993).

[14] K. Inomata, K. Yusu, and Y. Saito, Phys. Rev. Lett. 74, 1863 (1995).

[15] F. J. A. den Broeder and J. Kohlhepp, Phys. Rev. Lett. 75, 3026 (1995).

[16] J. Kohlhepp and F. J.A. den Broeder, J. Magn. Magn. Mater. 156, 261 (1996).

[17] A. Chaiken, R. P. Michel, and M. A. Wall, Phys. Rev. B 53, 5518 (1996).

[18] G. W. Anderson et al., Appl. Phys. Lett. 66, 1123 (1995).

[19] Cohesion in Metals: Transition Metal Alloys, edited by F. R. de Boer, R. Boom, W.C.M. Mattens, A.R. Miedema, and A. K. Niessen (North-Holland, Amsterdam, 1988).

[20] Z.P. Shi (private communication).

[21] For the (110) orientation, as for sputtered samples $[15,16]$, also an imaginary critical vector exists (along $\Gamma \mathrm{M})$. The given method of estimating the decay length yields the same value for this orientation. 